\title{
Capital Market Risk and the Dynamics of the Income Distribution
}

\author{
Martin W. Cripps* ${ }^{\dagger}$ \\ January 1999, revised May 1999.
}

\begin{abstract}
This paper introduces a dynamic model of the wealth distribution with risk aversion and aggregate risk in the capital market. It shows that aggregate risk increases the barriers to growth. It gives sufficient conditions for the long-run distribution of wealth to be independent of the initial income distribution. Credit rationing in the long run is consistent with these conditions. An arbitrarily small amount of aggregate uncertainty can change an economy from one where the initial conditions do matter, to one in which the long-run behaviour is independent of the initial conditions.
\end{abstract}

\section{Introduction}

This paper presents a dynamic model of the income distribution in a closed economy with aggregate risk. The first main result considers the model without aggregate risk and gives sufficient conditions for the income distribution to converge to a limit which is independent of the initial conditions. At this limiting distribution there is credit rationing, so in the long run there are a variety of production techniques being used. When there is aggregate risk the barriers to growth become more severe. This is because the flow of funds from risk-averse middle and high-income savers onto the capital market is reduced. The second result provides sufficient conditions for long-run incomes to be independent of the initial conditions when there is aggregate uncertainty. The final result shows that small amounts of aggregate risk generally decreases the dependence of the long-run behaviour on the initial conditions. Thus, the arguments for path-dependent growth may not be robust to the introduction of a little risk.

The first result gives sufficient conditions for the economy to converge to a limit that is independent of the initial income distribution when there is no aggregate risk. The sufficient conditions

\footnotetext{
${ }^{*}$ Deparment of Economics, University of Warwick, Coventry CV4 7AL, UK.

$\dagger$ My thanks are due to the ESRC Centre for the Study of Globalisation and Regionalisation for supporting this work. I would like to thank Keith Blackburn, Patrick Bolton, Martin Currie, Philip Trostel and seminar participants at Exeter, Manchester and Warwick Universities for their comments.
} 
we require are weaker than those found in previous studies. In particular the conditions we give allow for poor agents to be credit rationed at a zero rate of interest. This has two implications. First, there are poor economies where the capital market does not open (because no agent is wealthy enough to meet the credit rationing criterion), which will nevertheless grow and ultimately they will have active credit markets and converge to the limiting income distribution. Second, as there is credit rationing in the long-run, there will be a diversity of production technologies in the long run. There will always exist a poor class of agents who are forced to use an inefficient technology, because they are excluded from credit markets. The long-run inefficiency that arises from long-term credit rationing also gives scope for a Pareto improving government intervention, which will increase the long-run output and wealth of the economy.

The second set of results show that in spite of the stochastic aggregate shocks the long-run behaviour of the income distribution is independent of the initial income distribution. This occurs even though the aggregate risk increases the barriers to growth. We also show that the presence of a small amount of noise in the system decreases the dependence of the income distribution on the initial state. This suggests that models of non-ergodic growth should check whether their conclusions are robust to aggregate shocks.

In dynamic models of the income distribution the functioning of capital markets is the key issue. ${ }^{1}$ The common theme in these models is that growth is slowed by constraints on agents' ability to borrow to finance investment in new technology (credit rationing). In these models the demand side of the capital market is modelled in considerable detail, this gives a direct restriction on growth. However, the supply of funds to the capital market and its indirect effect on growth is considered in less detail: either there is an infinite supply at the prevailing world interest rate, or all savings in the economy get placed on the domestic capital market. ${ }^{2}$ This paper considers savings decisions in greater detail and how these may impact on growth. In the model below agents have alternative ways of saving and do not necessarily allocate their savings to the risky domestic capital market. In developing countries the supply of funds to the domestic capital market is just as important as the demand for loans. An under supply of capital may arise from various forms of capital flight, or from individuals choosing to store wealth in "safe" storable commodities such as land and gold. ${ }^{3}$ Broadly

\footnotetext{
${ }^{1}$ Banerjee and Newman (1991) and Galor and Zeira (1993) use an open capital market. Aghion and Bolton (1997) and Piketty (1997) use a closed capital market, so the market interest rate adjusts to equate the supply and demand for funds.

${ }^{2}$ An exception to this is Matsuyama (1998).

${ }^{3}$ The term "capital flight" is used very loosely here; it describes any means of storing wealth outside the domestic economy: it may be that domestic capital is held in overseas accounts or domestic capital may be held in foreign-
} 
speaking, the domestic capital market is just one asset the individual can invest in and portfolio decisions determine the allocation of savings among available means of storing wealth. Growth will, therefore, be contingent upon savers' willingness to place their savings on the domestic capital market.

The key features of the model below are risk aversion and capital market risk. The source of the capital market risk is the investment projects undertaken by borrowers. In previous models each individual's technology generated random and independent returns. There is a continuum of borrowers, so the law of large numbers applies and this idiosyncratic risk vanishes at the aggregate level. In such models the lending institutions feel no aggregate effect from the idiosyncratic risks and are able to pay a fixed rate of return to individuals who supply the funds. Below the outcomes of individuals' technology are correlated. This correlation does not vanish at the aggregate level, so lenders also bear aggregate risk. It follows that these lenders do not pay a certain rate of return to savers. When there is aggregate risk in the capital market, the capital supply from risk-averse agents will generally be less than that observed in the absence of aggregate risk. Risk averse agents will hedge the risk present in the domestic capital market by storing their wealth in a portfolio of assets; holding some of their wealth in a safe, storable commodity and some of their wealth in the country's capital market. The way in which agents make these portfolio choices will have significant implications for growth.

In the model below agents' propensity to avoid the capital market will depend upon their location in the wealth distribution, which has implications for trickle down growth. In general, asset market risk increases the barriers to long-run growth, by reducing the capital supply from the middle classes. The very poor (those on fixed subsistence incomes) will choose to hold all of their endowment in the risky capital market, because a large part of their life-time wealth is certain. Those with minimal inherited assets and a fixed lifetime's income can only invest this minimal amount in the capital market. They will choose to do this, because their lifetime's portfolio is dominated by the fixed element of their incomes. ${ }^{4} 5$ As poor individuals become richer the fixed component of their lifetime wealth becomes relatively smaller, so they allocate a smaller proportion of their total wealth to the capital market. The switching of savings away from the domestic capital market is most extreme when individuals are sufficiently wealthy to borrow to invest in risky technology. At this point they

\footnotetext{
denominated notes (e.g. dollars) within the country which cannot be used as a basis for making loans.

${ }^{4}$ This is a similar argument to economic justifications for gambling among the very poor.

${ }^{5}$ If subsistence labour income is also risky, this argument will not apply and the poor will also prefer to hedge this risk by using a storage technology.
} 
are so exposed to risk in their production decisions that (at the margin) they prefer to hold any additional wealth in a safe asset (or engage in capital flight). Ultimately, of course, when individuals are very wealthy and the technology risk is small relative to the size of their portfolio they will again supply funds to the capital market. Thus, (for a given rate of interest) the under supply of funds to the capital market in the presence of aggregate uncertainty becomes more pronounced when a poor economy gets richer. In the long run, however, when agents get sufficiently rich they will return to the capital market. Two forms of trickle down have been isolated: in Aghion and Bolton (1997) growth leads the rich to supply funds to poor borrowers, in Matsuyama (1998) the poor have raised returns to saving because the rich demand their capital. The relative importance of these two forms is affected by the presence of aggregate risk. The rich are already exposed to a lot of risk through their individual investment decisions, so when there is capital market risk they are less willing to supply savings to the capital market (they prefer capital flight or a storage technology). Thus to attract a given supply of capital the domestic interest rate must be higher and this higher rate of interest raises the rate of expected income growth of both the rich and the poor savers. Aggregate risk, therefore, tends to reduce the first form of trickle down and increase the second.

\section{The Model}

This section begins with a bald description of the preferences of agents and the technology available to them. Then the capital market is described. The first subsection describes the nature of the credit rationing in this model and how there will be three types of agents present in our model. There are the poor, who are credit rationed and obliged to use the subsistence technology. There is the middle class, who are borrowers and use the capital intensive technology, and there are the rich, who can afford to finance the use of capital intensive technology out of their own endowments. In each case we will describe the portfolio choices of the three types of individuals and how they make their bequests. The final subsection is devoted to writing down the (random) dynamic system for the wealth distribution that results from behaviour of the agents in this model. To do this it is necessary to describe the equilibrium in the asset markets.

In this model there is one good (a consumption good), a continuum of identical individuals with mass 1 (a generation) and each generation lives for one period. The consumption good is storable and does not depreciate between periods. An individual begins her existence at the start of a period and is endowed with one unit of labour and a wealth bequest from her mother. She then chooses how 
to invest her assets and which technology to use. At the end of the period she realises the returns from her investments and her productive activity, consumes, makes a bequest of the consumption good to her child and finally dies. Time is denoted $t=0,1,2, \ldots$. A generic wealth level is denoted $x \in[0, X]$, where $X$ is chosen to be a fixed upper bound on the feasible incomes generated by this system. To describe a wealth distribution at time $t$ we will use a probability measure $\lambda_{t}$ defined on $[0, X]$ and let $\Lambda$ denote the space of all (Borel) probability measures $\lambda_{t}$ on $[0, X] .{ }^{6}$ An agent's preferences, $u$, are defined on her consumption $c_{t}$ and her bequest of the consumption good to her child $x_{t+1}$;

$$
u\left(c_{t}, x_{t+1}\right)=\left(\frac{c_{t}^{\alpha} x_{t+1}^{1-\alpha}}{\alpha^{\alpha}(1-\alpha)^{1-\alpha}}\right)^{\gamma},
$$

where $0<\alpha<1$ and $0<\gamma<1$. If an agent realises $z$ units of the consumption good at the end of her life, then these preferences imply that she leaves a bequest of size $(1-\alpha) z$ and consumes $\alpha z$. Substitution shows that her indirect utility for the quantity of consumption good at the end of her life is $v(z)=z^{\gamma}$, so she has constant relative risk aversion.

There are two sources of income in the model. There is a subsistence technology. This technology does not require any labour it just provides individuals with $y$ units of income at the end of their life. Every individual receives $y$ simply by being alive, this subsistence income is specific to the individual and cannot be removed or seized by creditors. We will treat $y$ as being small and it represents the lowest level of income people can be certain of. There are also two types of capital-intensive technology one is more efficient than the other. Each capital-intensive technology requires $k$ units of the consumption good and one unit of labour. The output level of both technologies is risky and, unlike previous studies, correlated across projects. The returns to the capital intensive technologies are as follows. In the bad state of the world all capital-intensive technologies produce nothing; the bad state occurs with probability $1-\beta$. In the good state of the world technology 1 produces $G$ units of the consumption good with probability $\phi / \beta$ and 0 units with probability $1-\phi / \beta$, where $0 \leq \phi \leq \beta$. In the good state of the world technology 2 produces $B$ units of the consumption good with probability $\pi / \beta$ and 0 units with probability $1-\pi / \beta$. In good states the outcomes of the technologies are independent across agents. Technology 1 has a lower maximum level of output than technology 2. But, technology 1 gives a higher expected utility than storage which in turn gives a higher expected utility than technology 2. These assumptions are summarised in the following

\footnotetext{
${ }^{6}$ To be precise we will define $\lambda_{t}$ as a probability measure on the measurable space $([0, X], \mathcal{B})$, where $\mathcal{B}$ is the Borel sigma-algebra restricted to $[0, X]$.
} 
conditions:

$$
B>G, \quad \phi(G+y)^{\gamma}+(1-\phi) y^{\gamma}>(k+y)^{\gamma}>\pi(B+y)^{\gamma}+(1-\pi) y^{\gamma} .
$$

The outputs of the capital-intensive technologies are correlated across agents. The amount of correlation is determined by the parameter $\beta$; as $\beta \rightarrow 1$ the amount of correlation approaches zero and as $\beta \rightarrow \phi$ the correlation approaches unity. Notice that as $\beta$ varies the probability distribution over returns to the technology does not vary, so all technology choices are independent of $\beta$. The role of $\beta$ in the model is to represent the aggregate risk in making loans. As $\beta \rightarrow 1$ so all projects become independent of each other and the law of large numbers ensures that there is no aggregate risk in providing loans. However, when $\beta \rightarrow \phi$ the aggregate risk in providing loans is the same as the risk undertaken by the borrower.

The capital market in this closed economy is described by a mutual fund. Capital is supplied to the mutual fund by individuals allocating some of their wealth endowment to it. The mutual fund in turn supplies capital to individuals endowed with less than $k$ units of the consumption good who, nevertheless, want to use a capital-intensive technology and must borrow to finance the acquisition of the technology. There is free entry so the mutual fund makes zero profits. Investing in this mutual fund is risky, because in bad states all of the assets supplied to the fund will be lost. Let $r$ denote the rate of interest paid by the fund in good states, so every unit of the good supplied to the fund is repaid with $1+r$ units at the end of the period and every unit borrowed from the fund is repaid by $1+r$ units; the expected rate of return from the mutual fund is $\beta(1+r)$.

\subsection{Technology Choice, Credit Rationing and Portfolio Decisions}

In this economy there will be three types of individuals: those who only use the subsistence technology, those who borrow but use the capital-intensive technology and those who can use the capitalintensive technology without borrowing. Below we will describe each of these types' portfolio decisions, that is, how they allocate their inherited wealth between investing in the capital intensive technology, saving in the safe storage technology and investing in the risky mutual fund. And as agents' decisions to join each of the three groups is endogenous it is also necessary to describe what determines agents' decisions to become borrowers and lenders. We will treat each of these types in turn below.

First, we will study those individuals who borrow and use the capital-intensive technology. 
These individuals must make two choices: how much to borrow and which technology to use. These individuals borrow part, or all of the set up costs $k$ and can use their bequest $x$ to fund their investment also. The fund is unable to observe which project the borrowers use or what the returns to the project actually are. But the fund does have a liquidation technology which does not retrieve any of the borrower's assets, but simply ensures that borrowers receive only their subsistence income if the loan is not repaid. The fund liquidates all loans that are not paid back and borrowers are unable to renegotiate repayments ex-post. If the borrowers choose how much to borrow (and how much of $k$ to fund from their bequest), then they will always prefer to use their entire bequest to fund the investment and minimize the amount they borrow. ${ }^{7}$ Thus it is an optimal strategy for the borrowers to repay loans whenever they are able to. Borrowers prefer technology 1 to technology 2 when

$$
\phi[G+y+(1+r)(x-k)]^{\gamma}+(1-\phi) y^{\gamma}>\pi[B+y+(1+r)(x-k)]^{\gamma}+(1-\pi) y^{\gamma} .
$$

When $x=k$ this inequality is satisfied (by (1)), however as the left increases faster than the right there exists $\tilde{x}(r)<k$ such that

$$
\phi[G+y+(1+r)(\tilde{x}(r)-k)]^{\gamma}-\phi y^{\gamma}=\pi[B+y+(1+r)(\tilde{x}(r)-k)]^{\gamma}-\pi y^{\gamma} .
$$

Thus, as in Stiglitz and Weiss (1981), there is credit rationing for all individuals with wealth less than $\tilde{x}(r)$. The fund will not lend to borrowers with a bequest less than $\tilde{x}(r)$, because such borrowers will choose to use the inefficient technology. Only individuals with bequests satisfying $\tilde{x}(r) \leq x \leq k$ will be borrowers; when their project is successful their bequest is $(1-\alpha)(G+y+(x-k))$ and otherwise it is $(1-\alpha) y .^{8}$

The individuals who use only the subsistence technology choose how much of their bequest to allocate to the mutual fund and how much to keep in the consumption good. The very poorest of these allocate their entire bequest to the mutual fund and above a threshold level of bequest their investment in the mutual fund is an affine function (4) of the bequest $x$. Let $\theta$ denote the proportion of the endowment that is held in the mutual fund. A subsistence type's expected payoff is $\beta[y+x+\theta x r]^{\gamma}+(1-\beta)[y+x-\theta x]^{\gamma}$. The optimal $\theta$ (provided $0 \leq \theta \leq 1$ ) for subsistence

\footnotetext{
${ }^{7}$ If the investment project is unsuccessful they always receive income $y$, so expected utility is maximized by maximizing wealth from a successful investment project this is achieved by minimising the amount borrowed.

${ }^{8}$ The debt contract described here is not optimal, because the borrowers are risk averse. Generally, an optimal contract would offer the borrowers some insurance against the project being unsuccessful, but not complete insurance to prevent the borrower from choosing the bad technology. Such a contract would tend to increase the risk borne by the mutual fund and therefore increase the aggregate risk borne by the savers in this economy. Thus a truly optimal contract would tend to increase the effects ascribed to aggregate risk in this model.
} 
individuals satisfies

$$
x \theta=\frac{(1-\psi)(y+x)}{1+r \psi}, \quad \text { where } \psi=\left(\frac{1-\beta}{\beta r}\right)^{\frac{1}{1-\gamma}} .
$$

If the expected payoff from the mutual fund is greater than unity, $\beta(1+r)>1$, then $\psi<1$ and all individuals using the subsistence technology allocate some of their endowment to the mutual fund: $x \theta>0$. Moreover, the very poorest individuals will allocate all of their wealth endowment to the mutual fund, that is $\theta=1$ when

$$
x \leq \underline{x}:=\frac{1-\psi}{\psi(1+r)} y .
$$

The final type in our model are those individuals who are sufficiently wealthy to invest in the capital-intensive technology without borrowing $x>k$. It is always optimal for these individuals to choose the technology with the highest expected return and not to borrow, but they must also decide whether to use the capital intensive technology and what proportion of their remaining assets to allocate to the mutual fund. We begin by assuming these individuals do use the capital-intensive technology and will describe their portfolio choices. The individuals with inheritance close to $k$ do not invest in the mutual fund, because they are already exposed to a lot of risk from their technology choice. As individuals become richer they allocate more of their inheritance to this fund. Again let $\theta$ denote the proportion of their endowment (net of their investment costs) that they allocate to the mutual fund. Their expected payoff is

$$
\phi[G+y+(x-k)(1+r \theta)]^{\gamma}+(\beta-\phi)[y+(x-k)(1+r \theta)]^{\gamma}+(1-\beta)[y+(x-k)(1-\theta)]^{\gamma} .
$$

Let $\theta(x)$ denote the optimal value of $\theta$, when $0<\theta(x)<1$ it satisfies the first order condition

$$
\begin{aligned}
0=\phi & {\left[\frac{G+y}{x-k}+1+r \theta\right]^{\gamma-1} } \\
& +(\beta-\phi)\left[\frac{y}{x-k}+1+r \theta\right]^{\gamma-1}-\frac{1-\beta}{r}\left[\frac{y}{x-k}+1-\theta\right]^{\gamma-1} .
\end{aligned}
$$

The right is decreasing in $\theta$, so a necessary condition for the individual to allocate a positive proportion of her wealth to the mutual fund is that the right is positive when $\theta=0$. There exists a threshold wealth level $\bar{x}$, such that all individuals with bequests $k \leq x \leq \bar{x}$ do not invest in the mutual fund; $\theta(x)=0$ for $k \leq x \leq \bar{x}$. It is the case that $\bar{x}>k$ when the returns to the mutual fund are positive but not large. To be precise, when $0<\beta(1+r)-1<r \phi$ the threshold, $\bar{x}$, satisfies

$$
\left(\frac{\phi r+1-\beta(1+r)}{\phi r}\right)^{\frac{1}{1-\gamma}}=\frac{y+\bar{x}-k}{G+y+\bar{x}-k} .
$$


When the returns to the mutual fund are positive and sufficiently large $\beta(1+r)-1>r \phi$, then $\bar{x}=k$ and all the rich use the mutual fund. Also notice that (6) is positive for all $\theta$ when there is a

small amount of aggregate uncertainty, when $1-\beta$, is small, so in this case all of the rich put all of their assets in the capital market. In summary the function $\theta(x)$ will satisfy (6) for $x>\bar{x}$ and for $x \in[k, \bar{x}]$ it will have $\theta(x)=0$.

We will now show that all individuals prefer to use the capital intensive technology, if the interest rate is not too high. That is, the poor always want to borrow to use the capital intensive technology and the rich prefer to use the capital intensive technology rather than invest in the mutual fund. This establishes that the individuals who are excluded from the market for loans are definitely credit rationed. Although individuals' expected income must rise as result of undertaking the risky project, it is not immediately obvious that they strictly prefer to use the capital intensive technology, because this requires them to allocate a fixed part of their wealth to the risky technology which upsets their optimal pattern of risk allocation. Thus by using the risky technology they are constraining their portfolio choices. The conditions for the existence of credit rationing are an upper bound on the expected return to the mutual fund, $\beta(1+r)$ and a lower bound on the expected return to the capital intensive technology, because when $\beta(1+r)$ is high or $\phi G$ is low it is more attractive to invest in the mutual fund rather than to use the more risky technology 1.

Lemma 1 When (7) and (8) holds every individual prefers technology 1 and an optimal portfolio to using the subsistence technology with an optimal portfolio.

$$
\begin{aligned}
\phi^{1 / \gamma}(G+y) & >\beta(1+r)(k+y) \\
\phi^{1 / \gamma}\left[G+y\left(\frac{1+r \psi}{\psi(1+r)}\right)\right] & >\beta(1+r)\left[k+y\left(\frac{1+r \psi}{\psi(1+r)}\right)\right]
\end{aligned}
$$

Proof: See the Appendix.

\subsection{Capital Market Equilibrium and a Stochastic Process for Wealth}

The dynamics of the income distribution are determined by the map from the current income distribution to future income distributions. As there is aggregate uncertainty this map is state-dependent. There is one map that applies in good states and a different map that applies in bad states. The details of these two maps are determined by the equilibrium in the capital market and the optimal bequest behaviour described in the previous section. This section begins with a formal description 
of the state-dependent map from current wealth to future wealth in (9) and (10) below, then by writing down the expected evolution of the average level of wealth in (11). This Section ends with a formal description of the equilibrium interest rate (13).

In bad states the behaviour in the previous section induces the map (9) from current inheritance $x_{t}$ to next period's bequest $x_{t+1}$.

$$
x_{t+1}=(1-\alpha) \begin{cases}y, & x_{t} \leq x \\ \psi\left(1+r_{t}\right)\left(y+x_{t}\right)(1+r \psi)^{-1}, & \frac{x}{\tilde{x} \leq x_{t}<\tilde{x}} \\ y, & k \leq x_{t}<k \\ y+\left(1-\theta\left(x_{t}\right)\right)\left(x_{t}-k\right), & k\end{cases}
$$

The map (9) takes each wealth level in period $t$ to a wealth level in period $t+1$. This map thus takes an income distribution $\lambda_{t} \in \Lambda$ and maps it to an income distribution tomorrow $\lambda_{t+1} \in \Lambda$ conditional on a bad state having occurred. We will define $f: \Lambda \rightarrow \Lambda$ to be the map from today's income distribution to tomorrow's income distribution in the bad states. In good states the map from today's income level to tomorrow's depends upon whether the individual technology used was successful and produced output $G$ or failed and produced nothing.

$$
x_{t+1}=(1-\alpha) \begin{cases}y+\left(1+r_{t}\right) x_{t}, & x_{t} \leq \underline{x} \\ \left(1+r_{t}\right)\left(y+x_{t}\right)(1+r \psi)^{-1}, & \underline{x} \leq x_{t}<\tilde{x} \\ G+y+\left(1+r_{t}\right)\left(x_{t}-k\right), & \text { successful, } \tilde{x} \leq x_{t}<k \\ y, & \text { fails, } \tilde{x} \leq x_{t}<k \\ G+y+\left(x_{t}-k\right)\left(1+r \theta\left(x_{t}\right)\right), & \text { successful, } k \leq x_{t} \\ y+\left(1+r \theta\left(x_{t}\right)\right)\left(x_{t}-k\right), & \text { fails } k \leq x_{t} .\end{cases}
$$

This map again induces a map from today's income distribution $\lambda_{t} \in \Lambda$ to tomorrow's income distribution $\lambda_{t+1} \in \Lambda$ conditional on a bad state having occurred. We will define $F: \Lambda \rightarrow \Lambda$ to be this map.

A state of our system at time $t$ is a probability measure $\lambda_{t} \in \Lambda$. One way of summarising this measure is its mean or average $E_{\lambda_{t}} x:=\int x d \lambda_{t}$. The expectations, $E_{\lambda_{t}}$, are taken relative to the information available at the start of period $t$. Tomorrow's distribution of wealth is random from today's point of view, because it depends upon whether a good or a bad state occurred. Similarly, tomorrow's average wealth is random because it depends upon the state. We will let $E_{\lambda_{t}} x_{t+1}$ denote the expected value of the average wealth tomorrow, where expectations are taken relative to period t's state, from above we can write down the following relation for tomorrow's expected average wealth.

$$
\begin{aligned}
E_{\lambda_{t}} x_{t+1}= & (1-\alpha) y+\beta(1+r)(1-\alpha) E_{\lambda_{t}} x_{t} \\
& -(1-\alpha) \frac{\psi(1+r)}{1+r \psi}(\beta(1+r)-1) \int_{\underline{x}}^{\tilde{x}}(x-\underline{x}) d \lambda_{t}
\end{aligned}
$$




$$
\begin{aligned}
& +(1-\alpha) \int_{\tilde{x}}^{k} \phi G-\beta(1+r) k+(\beta-\phi)(1+r)(k-x) d \lambda_{t} \\
& +(1-\alpha) \int_{k}^{\infty} \phi G-\beta(1+r) k+(1-\theta)(1-\beta(1+r))(x-k) d \lambda_{t} .
\end{aligned}
$$

When $\beta=1$ no bad states occur and (11) describes a deterministic relationship between the average of the current income distribution and its average next period.

We assume that the capital market is closed. The equilibrium of the capital market in period $t$ determines the rate of interest $r_{t}$ as a function of the current wealth distribution $\lambda_{t}$. The supply of capital to the mutual fund comes from the subsistence individuals who invest and the very rich who invest.

$$
S_{t}(r):=\int_{0}^{\underline{x}} x_{t} d \lambda_{t}+\int_{\underline{x}}^{\tilde{x}} \frac{(1-\psi)\left(y+x_{t}\right)}{1+r \psi} d \lambda_{t}+\int_{k}^{\infty} \theta\left(x_{t}\right)\left(x_{t}-k\right) d \lambda_{t}
$$

The function $S_{t}(r)$ increases in $r{ }^{9}$ As no individual will enter the capital market when it yields a return less than the storage technology we must have $S_{t}(r)=0$ for $r+1<1 / \beta$. However, as $r+1$ approaches $1 / \beta$ from above capital may still be in positive supply when individuals are risk neutral. The demand for capital comes from the borrowers

$$
D_{t}(r):=\int_{\tilde{x}}^{k}\left(k-x_{t}\right) d \lambda_{t} .
$$

If there is a positive mass of individuals that want to borrow, $\int_{\tilde{x}}^{k} d \lambda_{t}>0$, then demand is a decreasing function of $r$ (as $\tilde{x}$ increases in $r$ ). When the rates of interest are low the demand will be positive and Lemma 1 shows that when is $r$ sufficiently high using the risky technology is less attractive than investing in the mutual fund. At this point the demand for capital jumps to zero and the supply of capital jumps up.

The capital market can be in two states: either there is a unique interest rate that equates the demand and supply of capital, or there is autarky where there is zero demand for capital at any interest rate that savers are willing to supply it. So, either there exists a unique interest rate $r_{t}>(1 / \beta)-1$ such that $D_{t}(r)=S_{t}(r)$, or there is zero demand for capital at any interest rate such that $(1+r) \beta>1$. It will prove useful to re-write the equation for $S_{t}(r)=D_{t}(r)$ in the following way

$$
E_{\lambda_{t}} x_{t}=\frac{\psi(1+r)}{1+r \psi} \int_{\underline{x}}^{\tilde{x}}(x-\underline{x}) d \lambda_{t}+k \int_{\tilde{x}}^{\infty} d \lambda_{t}+\int_{k}^{\infty}(1-\theta(x))(x-k) d \lambda_{t} .
$$

The equations (9), (10) and (13) together with an initial position $\lambda_{0}$ describe a stochastic process for the wealth distribution $\lambda_{t}$. With probability $1-\beta$ a current state $\lambda_{t} \in \Lambda$ is mapped

\footnotetext{
${ }^{9}$ As $\underline{x}$ decreases in $r, \tilde{x}$ increases in $r, \psi$ decreases in $r, \bar{x}$ decreases in $r$ and $\theta(x)$ increases in $r$.
} 
to a new wealth distribution $f\left(\lambda_{t}\right)$ described by the map (9) and capital market equilibrium (13). With probability $\beta$ current state $\lambda_{t} \in \Lambda$ is mapped to a new wealth distribution $F\left(\lambda_{t}\right)$ described by the map (10) and capital market equilibrium (13). The quadruple $\left(\lambda_{0}, \beta, f, F\right)$ defines a stochastic process on the state space $\Lambda$ starting at the initial distribution $\lambda_{0}$.

\section{The Evolution of the Distribution with No Aggregate Risk}

This section studies the dynamics of the system when $\beta=1$. The Proposition below gives sufficient conditions for the system to converge to a unique limiting distribution, that is, the long-run behaviour is independent of the initial income distribution. The limiting interest rate is zero. At this limit, however, there can be production inefficiency because there are individuals using the subsistence technology. This arises because the existence of a unique limit is consistent with credit rationing at zero interest rates. This result establishes an extension of the convergence result of Aghion and Bolton (1997). In their model the interest rate falls to zero, at which every agent can borrow, and the resultant linear Markov process converges to a unique ergodic distribution. In their paper it is essential for there to be no credit-rationing at zero interest rates, because otherwise there is a nonmonotone map from current wealth to future bequests and the results of Hopenhayn and Prescott (1992) do not apply. Proposition 1, below, shows that there is still convergence to a unique limiting distribution, even if there is credit rationing at zero interest rates. Thus the presence of credit rationing can be consistent with unique long-run behaviour. This contrasts with Piketty (1997) who derives multiple ergodic distributions for income in a model with long-run credit rationing.

When the parameters of the model imply that some poor individuals are credit rationed at zero interest rates, then it is possible that poor economies do not have a capital market at all. If no-one is rich enough to satisfy the credit-rationing condition, then the demand for capital is zero at all non-negative prices, although there are agents ready to supply capital at all non-negative prices. Thus our model will generate cases where there is no capital market in the early periods of growth of poor economies and that the capital market only comes into being when agents the economy are sufficiently wealthy.

The nature of the convergence used in this paper is strict. We will measure the distance between two income distributions using the strong topology rather than the weak topology. ${ }^{10}{ }^{11}$ If $\lambda, \lambda^{\prime}$ are

\footnotetext{
${ }^{10}$ Aghion and Bolton (1997) and Piketty (1997) establish convergence in the weak topology, because they apply the results of Hopenhayn and Prescott (1992). Sakuragawa and Mitsui (1999) study convergence in the strong topology.

${ }^{11}$ For descriptions of the strong and weak topology on distributions see Stokey and Lucas (1989) Chapters 11 and
} 
two income distributions in $\Lambda$ we will denote the distance between these distributions as

$$
\left\|\lambda-\lambda^{\prime}\right\|:=2 \sup _{B \in \mathcal{B}}\left|\lambda(B)-\lambda\left(B^{\prime}\right)\right|
$$

The distance between two distributions is an upper bound on the difference between the proportion of the population in any (Borel) set of incomes. ${ }^{12}$ The distance measure above can be used to define open sets in the state space $\Lambda$, we will let $\mathcal{L}$ denote the Borel sigma-algebra generated by these open sets.

The proof of the Proposition in this section is very different from the one in the next section, but in fact they both rely on the coupling of stochastic processes. This simple and intuitive approach to proving limit theorems for Markov processes is explained in Grimmett and Stirzaker (1982), for example, and is the basis of much modern work on stochastic processes. The proof of Proposition 1 proceeds in two stages (as in Aghion and Bolton 1997). In the first stage the rate of interest is shown to fall to zero in finite time and after this capital is in permanent excess supply. This part of the proof requires assumptions, because otherwise for some initial conditions it is possible that that the economy does not grow sufficiently quickly to drive interest rates to zero (this issue is studied in Piketty 1997). For this part of the proof to go through it is necessary to ensure that the expected returns to the investment project are sufficiently large for growth to be self-sustaining, $(1-\alpha) \phi G>k$. In the second part of the proof there is a permanent excess supply of capital and interest rates are always zero, so there are no aggregate changes in the dynamics and it is sufficient to study the evolution of one individual and all her descendants (a dynasty). We will show that once $r=0$ there is a strictly positive probability, $\omega>0$, such that after $n$ periods any two dynasties with initial levels of wealth, $x$ and $x^{\prime}$ have both been mapped to the income level $(1-\alpha) y$. This happens if all their investment projects are initially successful, so both of the dynasties' wealth levels converge to close to the maximum feasible, then they both experience a sequence of unsuccessful projects until they are both borrowers with an unsuccessful project. All borrowers with unsuccessful projects are mapped to income levels $(1-\alpha) y$. When the dynasties have been simultaneously mapped to the wealth level $(1-\alpha) y$ the future distributions of wealth for these two dynasties are identical (by the Markov structure). For any two individuals there is a probability of at most $1-\omega<1$ that their successors' wealth levels do not have identical distributions after $n$ periods. After $m n$ periods, therefore, there is a probability of at most $(1-\omega)^{m}$ that their successors' wealth levels do 12, for example. This also gives examples of sequences that converge in the weak topology but not the strong topology. ${ }^{12}$ This metric induces a complete topology on the state space $\Lambda$. 
not have identical distributions. It follows that any two individuals eventually have identical wealth distributions, and that convergence is exponentially fast.

The Proposition below uses the notation $\tilde{x}_{0}$ for $\tilde{x}$ when $r=0$. There is no credit rationing at the zero interest rate if $\tilde{x}_{0}<(1-\alpha) y$, so all individuals are able to borrow. The proposition assumes that $\tilde{x}_{0}<(2-\alpha)(1-\alpha) y$. Thus there can be credit rationing. This condition is sufficient for the subsistence class to acquire enough savings in one life time to satisfy the credit rationing constraint. It seems likely that an even weaker condition will work where it takes a finite number of periods to leave the subsistence class at zero interest rates, but this requires a great deal of additional work.

Proposition 1 Suppose $\beta=1,(1-\alpha)(2-\alpha) y>\tilde{x}_{0},(1-\alpha) \phi G>k$, and $(1-\alpha)\left(\phi^{2} G+\right.$ $y)>k$ then:

(1) If $\lambda_{0}, \lambda_{0}^{\prime} \in \Lambda$ then $\left\|\lambda_{t}-\lambda_{t}^{\prime}\right\| \rightarrow 0$, where $\lambda_{t}\left(\lambda_{t}^{\prime}\right)$ is the state at time $t$ of the process starting in state $\lambda_{0}\left(\lambda_{0}^{\prime}\right)$

(2) $r_{t}=0$ for all $t>k y^{-1}(1-\alpha)^{-1}$.

Proof: See the Appendix.

\section{The Evolution of the Distribution with Aggregate Risk}

This section starts with a discussion of the short-run effects of aggregate uncertainty, which is then summarized in Lemma 2. After these comparative statics there are two Propositions. These give sufficient conditions for the stochastic process governing the income distribution to converge to unique limiting behaviour. Proposition 2 considers the case where the aggregate risk in the model generates substantial barriers to growth. It describes sufficient conditions for the long-run to be independent of the initial distribution. This proposition requires that there is no credit rationing when $r=0$, so the capital market will always open. Proposition 3 shows that if the aggregate uncertainty is sufficiently small, then the long-run behaviour of wealth is independent of the initial distribution even when the economy can generate credit rationing at zero interest rates. Thus, for the present specification of aggregate uncertainty, arbitrarily small amounts of uncertainty will ensure long-run behaviour that is independent of the initial distribution. The section ends with an informal description of the stationary behaviour of the income distribution in this model.

We will begin by presenting some short-run comparative-statics results. We will show that 
small amounts of aggregate risk have no effect on the interest rates in poor economies, although risk increases the equilibrium interest rate in general. At a given state, $\lambda_{t}$, aggregate demand for capital is independent of aggregate risk, because the amount of credit rationing, $\tilde{x}$, depends on the idiosyncratic risk of projects not on the level of aggregate risk. (The idiosyncratic risk determines an agent's choice between projects not the aggregate risk.) However, the supply of capital, at a given interest rate, does depend on the amount of aggregate uncertainty. Investors will supply less savings to the mutual fund as risk increases, so the capital supply curve shifts inwards as risk rises while the upward sloping demand curve stays fixed. Consequently, the equilibrium rate of interest cannot fall in response to an increase in aggregate risk. An extreme case arises when the economy is poor and the aggregate risk is small. In this case the subsistence class are the only suppliers of capital and are unable to adjust their portfolio of assets optimally, because of credit rationing. The credit-rationed individuals are rationed in their ability to take risks. The only opportunity they have to take risks is in supplying assets to the mutual fund. They, therefore, supply all their savings to this fund and will continue to do so if the amount of aggregate risk changes a little. In consequence the supply of capital to the mutual fund is independent of the level of aggregate risk when there are no rich individuals. In poor economies the credit constraint (and the implicit constraint on risk bearing this imposes) drives an equilibrium in the asset market where the poor savers are willing to absorb any small changes in aggregate asset-market risk. Thus trickle-up growth is still strong in the presence of aggregate risk. The final part of the Lemma shows that trickle down growth (when savers are generally rich while borrowers are poor) can be strengthened by aggregate risk. It is possible to find states where aggregate risk is beneficial for income growth. In sufficiently rich economies, where there is enough capital for every low-income individual, aggregate uncertainty raises income growth. When there is no credit rationing the rich supply the funds for the poor borrowers, an increase in aggregate risk leads the rich to demand a higher rate of interest on these loans. Consequently, aggregate uncertainty (when there is no credit rationing) leads to a re-distribution of wealth from borrowers to savers. The preceding discussion is made precise in the following Lemma.

Lemma 2 Fix a state $\lambda_{t} \in \Lambda$.

(1) The equilibrium interest rate, $r$, does not increase in $\beta$. If $\int_{k}^{\infty} d \lambda_{t}=0$, then there exists a $\bar{\beta}<1$, such that the equilibrium interest rate is independent of $\beta$, for $\beta \in[\bar{\beta}, 1]$.

(2) If $\int_{k}^{\infty} d \lambda_{t}=0$ and $\phi(1-\alpha) G \geq k$, then $\Delta_{t}:=E_{\lambda_{t}} x_{t+1}-E_{\lambda_{t}} x_{t}>(1-\alpha) y$ when $\beta \in[\bar{\beta}, 1]$ and $\Delta_{t}$ is increasing in $\beta$. Also, $\Delta_{t}$ is increasing in $\beta$ if $\lambda_{t}$ has a continuous 
density and $\beta \rightarrow \phi$.

(3) If $\int_{0}^{\tilde{x}} d \lambda_{t}=0$ and $\lambda_{t}$ has a continuous density, then an increase in $\beta$ decreases $E_{\lambda_{t}} x_{t+1}$

if $E_{\lambda_{t}} x_{t}$ is sufficiently high.

Proof: See the Appendix.

It is difficult to describe the effect of aggregate risk on the long-run behaviour, because the long-run behaviour of the model is described by a distribution over a space of measures, $\Lambda$. We will show that the limiting behaviour of the income distribution $\lambda_{t}$ is independent of the initial income distribution and that the rate of convergence to this limiting behaviour is exponential. Thus, the long-run behaviour of the income distribution is unaffected by the initial state of the system. That is not to say, however, that the income distribution or the rate of interest becomes constant as time passes. This could never be the case, as the aggregate uncertainty in the model continues to shock the wealth distribution. Instead there is a stationary distribution of the states $\lambda_{t} \in \Lambda$ and each realisation of the stochastic process converges exponentially fast to this stationary distribution. The convergence of the states $\lambda_{t}$ to a stationary distribution is not sufficient, however, to show that individuals within the economy have equal chances of being rich and being poor. In general, it is possible for the states $\lambda_{t}$ to converge to behaviour that is independent of the initial distribution, but for individual's incomes within the distribution to depend on the initial condition. (For example, if the individual with the lowest income always had the lowest income.) Our proof will also show that not only will the long-run behaviour of $\lambda$ be independent of the initial state, but so will individuals' incomes within the distribution be independent of their initial position.

The proofs of convergence will again use the coupling of stochastic processes. The first step in the proof of Proposition 2 is to show that there is a finite number $N$, such that if there are $N$ consecutive bad states the entire income distribution is concentrated at the point $(1-\alpha) y$. All individuals will have wealth less than $k$ after a finite number of bad states, because successive failures of the capital intensive technology will eventually destroy the richest generation's asset stock. Because the capital markets are always open, the richest individuals borrow and the poorest lend if all individuals have wealth less than $k$. In bad states the borrowers always leave a bequest of $(1-\alpha) y$. We show that individuals with inherited wealth $(1-\alpha) y$ use the subsistence technology and invest all of their wealth in the mutual fund, so in the bad state their savings are constantly being destroyed and they can never leave a bequest of more than $(1-\alpha) y$. The borrowers also end up at the lowest wealth after 
one bad state, thus the stock of people at the lowest inherited wealth level grows and includes the entire population in a finite number of periods. Once this is established, for any two initial income distributions there is a probability $(1-\beta)^{2 N}$ (the probability that they both have $N$ successive bad states) that after $N$ periods they are both concentrated at $(1-\alpha) y$. Once they are both concentrated at $(1-\alpha) y$ the future evolution of these distributions must be identical because they have both started from the same point. This implies there is a probability of at most $1-(1-\beta)^{2 N}$, that after $N$ periods the future evolution of the income distribution is not identical. After $M N$ periods, therefore, there is at most a probability $\left[1-(1-\beta)^{2 N}\right]^{M}$ that the distributions of the income distributions are not identical. As $M$ tends to infinity there is a zero probability that the income distributions are not identical. This argument shows that, independent of the initial distribution, ultimately all income distributions must be evolving in an identical fashion and that the rate of convergence is exponential. Three assumptions are necessary for this argument to work. The first is that bad states do not occur with probability greater than one half and that $\tilde{x}_{0}<(1-\alpha) y$, which ensures the capital market continues to open no matter how poor the economy is. The second is that the bequest of an individual with one period's subsistence income is insufficient to finance a capital purchase. The final condition in the Proposition, (14), ensures that all individuals with inherited wealth $(1-\alpha) y$ put all their inheritance in the mutual fund.

Conditional on two initial wealth distributions, $\lambda_{0}$ and $\lambda_{0}^{\prime}$ say, the state of the system at time $t$ is a random variable, denoted $\lambda_{t}$ or $\lambda_{t}^{\prime}$, that can take a finite number of values. The values taken by these random variables are determined by the sequence of good and bad states that actually occur. In the Proposition we will use the expression $E_{0} \lambda_{t}$, respectively $E_{0} \lambda_{t}^{\prime}$, to denote expectations of $\lambda_{t}$, $\lambda_{t}^{\prime}$, taken over the values of the stochastic process governing good and bad states, but conditional on the initial state $\lambda_{0}, \lambda_{0}^{\prime}$. Thus $E_{0}\left\|\lambda_{t}-\lambda_{t}^{\prime}\right\|$ is the expected distance (using the strong topology) between the states at time $t$ for two different initial conditions.

Proposition 2 Assume that $1>\beta>1 / 2, \tilde{x}_{0}<(1-\alpha) y<k$ and

$$
\frac{k-y(1-\alpha)}{\beta-(1-\alpha)(1-\beta)(1-\gamma)}<\frac{\phi G-\pi B}{\phi-\pi} \text {. }
$$

Let $\lambda_{t}$ be the state of the stochastic process $\left(\lambda_{0}, \beta, f, F\right)$ at time $t$ and let $\lambda_{t}^{\prime}$ be the state of the stochastic process $\left(\lambda_{0}^{\prime}, \beta, f, F\right)$ at time $t$, for $\lambda_{0}, \lambda_{0}^{\prime} \in \Lambda$. Then $E_{0}\left\|\lambda_{t}-\lambda_{t}^{\prime}\right\| \rightarrow 0$.

Proof: See the Appendix. 
The proof of this proposition shows that at some time the income distribution is concentrated at $(1-\alpha) y$, but this does not mean that the income distribution continues to be a point mass. There are two mechanisms whereby the point mass is spread out, the first arises because of the random returns to the high technology. Some individuals will have successful projects and others will not, although they have exactly the same wealth. The second arises because of credit rationing. Equilibrium in the capital market can force individuals with identical incomes to be on each side of the capital market. This again spreads out the future income distribution for individuals with identical current income. These two mechanisms treat identical individuals identically, so the way in which the income distribution gets spread out means that all individuals do have equal probability of being at different points in the wealth distribution. This is why we claimed earlier that not only are the states, $\lambda_{t}$, independent of the initial position in the long run, but so too is an individual's relative location in the income distribution independent of her initial location.

Proposition 3 considers the model with an arbitrarily small amount of aggregate risk. It again shows that the long-run behaviour of the income distribution is independent of the initial income distribution. The intuition for this proposition is as follows. If the rate of interest is strictly bounded away from zero and the amount of aggregate risk is small then all individuals will put all of their assets into the mutual fund. So, one bad state will eliminate all asset holdings by all individuals and drive everyone in the economy to the wealth level $(1-\alpha) y$. However, this argument will only work if the rate of interest is sufficiently high, that is, if there is a significant under supply of capital. The proof of the Proposition is again based on coupling. It constructs a sequence of states, some bad and one good, that steers two arbitrary initial states to a position where capital is under supplied. Then, the final bad state occurs and both economies are simultaneously mapped to the same wealth distribution. The additional assumption (15) is made to guarantee the existence of a state where capital is under supplied. This assumption will fail to hold when $G$ is very large or if $k$ is small relative to $y$. Of course, if (15) fails and capital is always in excess supply then there is no real problem of growth, so this assumption is actually makes it harder for economies to grow.

Proposition 3 Assume either (a) $\tilde{x}_{0}<(1-\alpha) y$, or (b) $(1-\alpha)(2-\alpha) y>\tilde{x}_{0}$ and

$$
\left[k-(1-\alpha) y\left(\alpha^{2}-3 \alpha+3\right)\right]^{2}>G(2-\alpha)(1-\alpha)^{2} y
$$

If $\lambda_{0}, \lambda_{0}^{\prime} \in \Lambda$ are two different initial income distributions and $\lambda_{t}$ and $\lambda_{t}^{\prime}$ are the states of 
these processes at time $t$. Then there exists a $\underline{\beta}<1$ such that for all $\beta \in(\underline{\beta}, 1)$

$$
E_{0}\left\|\lambda_{t}-\lambda_{t}^{\prime}\right\|<\left[1-(1-\beta)^{2}\right]^{t}, \quad \forall \lambda_{0}, \lambda_{0}^{\prime} \in \Lambda
$$

Proof: See the Appendix.

We have shown that the initial conditions do not affect the long-run behaviour of the model, but so far have said little about what actually happens in the long run. In particular does the economy grow, or is it always stuck in a subsistence state? The proofs above show that eventually the economy must visit a state where the income distribution is concentrated at $(1-\alpha) y$, let us call this the primal state. As all economies must eventually visit this primal state, economies will only progress beyond subsistence in the long run if they are able to grow away from the primal state. Suppose that the economy has experienced a sequence of bad states, which have driven it to the primal state. Also suppose that the bad states are sufficiently improbable for there to be many good states following this. In general, the conditions given in Proposition 2 do not prevent the economy from getting stuck at low wealth, high interest rates and few people using the low technology after visiting the primal state. Conditions resembling those in Proposition 1, or 3 , are necessary if the wealth in the economy is to grow, so that there is a net increase in wealth in the economy. The underlying risk makes this growth slower, because there are higher interest rates and fewer savers investing in the asset market (see Lemma 2). But more risk will not affect the net increase in wealth in good states. The underlying risk also changes the shape of the wealth distribution. After many good states it makes the rich richer, because they can always get a positive rate of return on their savings (whereas $r=0$ if there is no risk) and it makes the subsistence types richer as there is a positive rate of interest in the long run. The middle classes, however, are made poorer. Ultimately, another sequence of bad states occurs and the economy is driven back to the primal state and the whole process begins again.

\section{Conclusions}

We can draw the following conclusions from the above: The persistence of credit rationing is quite compatible with ergodic behaviour of the income distribution. Aggregate risk in dynamic models of the income distribution impacts on agents capital supply decisions and thereby has the potential to slow the rate of growth of incomes. A small amount of aggregate risk is quite compatible with ergodic growth and can make ergodic growth more likely. 


\section{References}

Aghion, P. And P. Bolton (1997): "A Theory of Trickle-Down Growth and Development", Review of Economic Studies, 64, 151-172.

BanerJee, A.V. And Newman, A.F. (1991): "Risk-Bearing and the Theory of Income Distribution", Review of Economic Studies, 58, 211-255.

Diamond, D.W. (1989): "Reputation Acquisition in Debt Markets", Journal of Political Economy, 97, 828-862.

Galor, O. And J. Zeira (1993): "Income Distribution and Macroeconomics", Review of Economic Studies, $60,35-52$.

Grimmett. G. R. And D. R. Stirzaker (1982): "Probability and Random Processes", Oxford University Press, Oxford.

Hopenhayn, H. And E. Prescott (1992): "Stochastic Monotonicity and the Stationary Distributions for Dynamic Economies", Econometrica, 60, 1387-1406.

Matsuyama, K. (1998): "Endogenous Inequality", mimeo, Department of Economics, Northwestern University.

PiketTy, T. (1997): "The Dynamics of the Wealth Distribution and the Interest Rate with Credit Rationing", Review of Economic Studies, 64, 173-190.

Sakuragawa, M. And S. Mitsui (1999): "Long-Run Wealth Distribution under Capital Market Imperfection and the Role of Interest Rate", mimeo, Faculty of Economics, Nagoya City University, Japan.

Stiglitz, J.E. AND A. Weiss (1981): "Credit Rationing in Markets with Imperfect Information", American Economic Review, 71, 393-410.

Stokey, N. L. And R. E. Lucas (1989): Recursive Methods In Economic Dynamics, Harvard University Press, Cambridge, Mass.

\section{Appendix}

\section{PROOF OF LEMMA 1}

From the text an individual's expected utility from the subsistence technology (and an optimal portfolio) is $\beta(y+x)^{\gamma}(1+r)^{\gamma}(1+r \psi)^{1-\gamma}$, when $x>\underline{x}$. (When $x \in[0, \underline{x}$ this over estimates the utility obtained from using the subsistence technology, because these individuals are constrained in their portfolio decisions.)

Consider individuals with $0 \leq x \leq k$. Their expected utility from borrowing is $\phi[G+y+(1+$ $r)(x-k)]^{\gamma}+(1-\phi) y^{\gamma}$. For all $x \in[0, k]$ a sufficient condition for borrowing to be better than subsistence is

$$
\phi[G+y+(1+r)(x-k)]^{\gamma} \geq \beta(1+r \psi)\left(\frac{(y+k)(1+r)}{1+r \psi}\right)^{\gamma}, \quad x \in[0, k] .
$$


Raise both sides to the power $1 / \gamma$, then the left and the right of (A.1) are linear functions of $x$, and the slope of the function on the left is less than the slope of the function on the right (as $\phi<\beta$ and $\psi>0$ ). A necessary and sufficient condition for (A.1) is, therefore, found by setting $x=k$ in (A.1). Some rearranging of (A.1) with $x=k$ gives the condition

$$
\phi^{1 / \gamma}(G+y) \geq \beta(y+x)(1+r)\left(\beta+(1-\beta) \psi^{\gamma}\right)^{\frac{1-\gamma}{\gamma}} .
$$

As $\psi, \gamma, \beta \in[0,1]$ the condition (7) is sufficient for this.

Now consider individuals with $k<x<k+y(1-\psi) / \psi(1+r)$. If these individuals use the risky technology and do not invest in the capital market $(\theta=0)$ they have the expected utility $\phi(G+y+x-k)^{\gamma}+(1-\phi)(y+x-k)^{\gamma}$. Their expected utility from the subsistence technology is given above, thus a sufficient condition for these individuals to use the risky technology is

$$
\phi(G+y+x-k)^{\gamma} \geq \beta(1+r \psi)\left(\frac{(y+k)(1+r)}{1+r \psi}\right)^{\gamma}, \quad x \in\left[k, k+y \frac{1-\psi}{\psi(1+r)}\right] .
$$

A similar argument to the one used above now applies. Raise both sides to the power $1 / \gamma$ and then compare the slopes. A sufficient condition for the above is that it holds when $x=k+y(1-\psi) / \psi(1+r)$. Using the fact that $\beta(1+r \psi)<1$ we get the sufficient condition (8).

Now consider individuals with $x>k+y(1-\psi) / \psi(1+r)$. A feasible portfolio policy for these individuals is to choose $\theta(x-k)=(y+x-k)(1-\psi) /(1+r \psi)$. The expected payoff from such a portfolio is

$$
\phi\left[G+(y+x-k) \frac{1+r}{1+r \psi}\right]^{\gamma}+(y+x-k)^{\gamma}\left(\frac{1+r}{1+r \psi}\right)^{\gamma}\left[\beta-\phi+(1-\beta) \psi^{\gamma}\right] .
$$

As $(1-\beta) \psi^{\gamma}=r \beta \psi$, this expression is greater than the expected payoff from using the subsistence technology if and only if

$$
\frac{\phi}{\beta(1+r \psi)}\left[G\left(\frac{1+r \psi}{1+r}\right)+y+x-k\right]^{\gamma}+\frac{\beta-\phi+r \beta \psi}{\beta(1+r \psi)}(y+x-k)^{\gamma} \geq(y+x)^{\gamma} .
$$

This holds if and only if an individual with constant relative risk aversion and initial wealth $y+x$ wants to take a gamble that costs $k$ and pays out $G(1+r \psi) /(1+r)$ with probability $\phi / \beta(1+r \psi)$. All individuals with wealth $y+x \geq k$ will take this constant gamble, if and only if the individual with the lowest wealth $y+x=k$ does. That is, if

$$
\phi G^{\gamma} \geq \beta(1+r \psi)^{1-\gamma}(1+r)^{\gamma} k^{\gamma} .
$$

As $\beta(1+r \psi)<1$ a sufficient condition for this is $\phi^{1 / \gamma} G>\beta k(1+r)$. As $\phi^{1 / \gamma}<\beta(1+r)$ this is implied by the condition (7).

Q.E.D. 


\section{$\underline{\text { Proof of Proposition } 1}$}

If $\beta=1$ then $\underline{x}=\tilde{x}$ and $\theta(x)=1$ for all $x$. The condition for equilibrium in the capital market (13) is

$$
E_{\lambda_{t}} x_{t}=k \int_{\tilde{x}}^{\infty} d \lambda_{t}
$$

This equality can only be satisfied if $E_{\lambda_{t}} x_{t} \leq k$. (If the above fails, then the supply of capital exceeds the demand at any positive interest rate and $r=0$.) When the capital market clears we can use (13) to substitute for $E_{\lambda_{t}} x_{t}$ into (11). Then using the fact that $\beta=1$ gives

$$
E_{\lambda_{t}} x_{t+1}-E_{\lambda_{t}} x_{t}=(1-\alpha)\left[y+(1+r)(1-\phi) \int_{\tilde{x}}^{k}(k-x) d \lambda_{t}\right]+[(1-\alpha) \phi G-k] \int_{\tilde{x}}^{\infty} d \lambda_{t} .
$$

$\beta=1$ implies that tomorrow's average income is known today, $E_{\lambda_{t+1}} x_{t+1}=E_{\lambda_{t}} x_{t+1}$. The above, therefore, implies that average income grows by at least $(1-\alpha) y$ each period that capital markets clear. There can be at most $T=k y^{-1}(1-\alpha)^{-1}$ successive periods when the capital market clears, average income grows by $(1-\alpha) y$ and $E_{\lambda_{t}} x_{t} \leq k$. So, there is a finite time period $t$ when there is excess supply of capital, $r_{t}=0$ and $E_{\lambda_{t}} x_{t}>k \int_{\tilde{x}_{0}}^{\infty} d \lambda_{t}$. Period $t+1$ 's average wealth is described by (11) with $r=0$

$$
E_{\lambda_{t}} x_{t+1}=(1-\alpha)\left(y+E_{t} x_{t}+(1-\phi) \int_{\tilde{x}_{0}}^{k}(k-x) d \lambda_{t}+\int_{\tilde{x}_{0}}^{\infty} \phi G-k d \lambda_{t}\right) .
$$

Capital is in excess supply in period $t+1$ if $E_{\lambda_{t}} x_{t+1}>k \int_{\tilde{x}_{0}}^{\infty} d \lambda_{t+1}$. We will give an inductive proof to show that if capital is in excess supply in period $t$ it must also be in excess supply in period $t+1$.

Substituting the above expression for $E_{\lambda_{t}} x_{t+1}$ into the condition for an excess supply of capital in period $t+1$ gives

$$
k \int_{\tilde{x}_{0}}^{\infty} d \lambda_{t+1}<(1-\alpha)\left(y+E_{t} x_{t}+(1-\phi) \int_{\tilde{x}_{0}}^{k}(k-x) d \lambda_{t}+\int_{\tilde{x}_{0}}^{\infty}(\phi G-k) d \lambda_{t}\right) .
$$

As $E_{\lambda_{t}} x_{t}>k \int_{\tilde{x}_{0}}^{\infty} d \lambda_{t}$ in period $t$ a sufficient condition for this is

$$
k \int_{\tilde{x}_{0}}^{\infty} d \lambda_{t+1}<(1-\alpha)\left(y+(1-\phi) \int_{\tilde{x}_{0}}^{k}(k-x) d \lambda_{t}+\int_{\tilde{x}_{0}}^{\infty} \phi G d \lambda_{t}\right) .
$$

As $\int_{\tilde{x}_{0}}^{k}(k-x) d \lambda_{t} \geq 0$ the following is a sufficient condition for this inequality.

$$
k<(1-\alpha) y+(1-\alpha) \phi G \int_{\tilde{x}_{0}}^{\infty} d \lambda_{t}
$$

The assumption that $(2-\alpha)(1-\alpha) y>\tilde{x}_{0}$ implies that the only individuals born with inheritances in the interval $\left[(1-\alpha) y, \tilde{x}_{0}\right]$ are the daughters of individuals with failing projects, so $\int_{0}^{\tilde{x}_{0}} d \lambda_{t} \leq$ 
$1-\phi$. This gives a lower bound on $\int_{\tilde{x}_{0}}^{\infty} d \lambda_{t}$. Combining all of this we get the sufficient condition $k<(1-\alpha)\left[y+\phi^{2}\right] G$, which is true by assertion.

Once $r=0$ the income distribution evolves according to the linear map

$$
x_{t+1}=(1-\alpha)\left\{\begin{array}{ll}
y+x, & x_{t}<\tilde{x}_{0} \\
G+y+x_{t}-k, & \text { successful, } \tilde{x}_{0} \leq x_{t}<k \\
y, & \text { fails, } \tilde{x}_{0} \leq x_{t}<k \\
G+y+x_{t}-k, & \text { successful, } k \leq x_{t} \\
y+x_{t}-k, & \text { fails } k \leq x_{t}
\end{array} .\right.
$$

There exists a finite $N$ such that $N$ successive failures of the technology drives a dynasty with wealth $(1-\alpha)(G+y-k) / \alpha$ to an endowment $x \in\left(\tilde{x}_{0}, k\right)$. This is because successive failures eventually drive a dynasty's wealth below $\tilde{x}_{0}$ and the assumption on $\tilde{x}_{0}$ and $k$ imply that individuals with wealth in the interval $\left[(1-\alpha) y, \tilde{x}_{0}\right)$ are borrowers next period. For $\epsilon>0$ sufficiently small, $N$ successive failures of the technology drives a dynasty with initial wealth within $\epsilon$ of $(1-\alpha)(G+y-k) / \alpha$ to an endowment in $\left(\tilde{x}_{0}, k\right)$.

Consider a dynasty with initial income $x \in[0, X]$. It takes any dynasty only one lifetime to become a borrower if it is on a subsistence income, so after $M+1$ successes the dynasty's current generation has an endowment $x_{M}$ which satisfies.

$$
\left|x_{M}-\frac{1-\alpha}{\alpha}(G+y-k)\right| \leq(1-\alpha)^{M}\left|(1-\alpha)(x+y)-\frac{1-\alpha}{\alpha}(G+y-k)\right|
$$

(Recall that $(1-\alpha)(x+y)$ is the bequest after one period of subsistence.) There exists a finite value of $M$ so that the right of the above is less than $\epsilon$ for all $x \in[0, X]$. Thus for a finite $M$ and a finite $N$ (from the last paragraph) a sequence of $M+1$ successes and then $N$ failures of technology drives a dynasty with initial wealth $x$ to an endowment in the interval $\left(\tilde{x}_{0}, k\right)$. At this point the dynasty is a borrower and a further failure of the technology drives it to an endowment $(1-\alpha) y$. There is a probability $\zeta:=\phi^{M+1}(1-\phi)^{N+1}$ that in any $M+N+2$ periods the dynasty is driven to endowment $(1-\alpha) y$.

Consider two dynasties with initial wealth $x$ and $x^{\prime}$. Let $\mu_{x}^{t} \in \Lambda$ (respectively $\mu_{x^{\prime}}^{t} \in \Lambda$ ) denote the distribution of the dynasty's endowment at time $t$ when it had initial wealth $x$ (respectively $x^{\prime}$ ). Then for $t=M+N+2$ there is a probability of at least $\zeta^{2}$ that both dynasties have been mapped to endowment level $(1-\alpha) y$ in period $t$. Once this has happened the Markov property implies that the future distributions of these dynasty's wealth are identical. Thus the two probability measures in all periods $t \geq M+N+2$ can only differ with probability at most $1-\zeta^{2}$. 


$$
\left\|\mu_{x}^{t}-\mu_{x^{\prime}}^{t}\right\| \leq\left(1-\zeta^{2}\right) 1 \quad \forall t \geq M+N+2, \quad x, x^{\prime} \in[0, X]
$$

If $t \geq d(M+N+2)$, then there are at least $d$ independent opportunities for the two processes to be driven to the endowments $(1-\alpha) y$. By iterating this idea we find that, whatever the initial state, the Markov process converges exponentially to a unique stationary distribution.

$$
\left\|\mu_{x}^{t}-\mu_{x^{\prime}}^{t}\right\| \leq\left(1-\zeta^{2}\right)^{d} 1 \quad \forall t \geq d(M+N+2) \quad x, x^{\prime} \in[0, X]
$$

Q.E.D.

\section{ProOF OF LEMMA 2}

Part (1): The proof that $r$ does not increase in $\beta$ follows from the discussion, so it remains to prove the rest of the Lemma. Since $\lim _{\beta \rightarrow 1} \underline{x}=\infty$ and $\tilde{x} \leq k$ is independent of $\beta$, for all states $\lambda_{t}$ there is an interval $\bar{\beta} \leq \beta \leq 1$ with strictly positive Lebesgue measure such that $\underline{x} \geq k \geq \tilde{x}$. When $\underline{x}>\tilde{x}$ and $\int_{k}^{\infty} d \lambda_{t}=0$ the condition for credit market equilibrium is

$$
E_{\lambda_{t}} x_{t}=k \int_{\tilde{x}}^{\infty} d \lambda_{t}
$$

Both sides of this are independent of $\beta$, so the equilibrium value of $r$ is too.

Part (2): We can use (13) to substitute out $E_{\lambda_{t}} x_{t}$ in (11). When $\lambda_{t}([k, \infty))=0$ this gives

$$
\begin{aligned}
E_{\lambda_{t}} x_{t+1}-E_{\lambda_{t}} x_{t}= & (1-\alpha) y-\frac{\alpha \psi(1+r)}{1+r \psi} \int_{\underline{x}}^{\tilde{x}}(x-\underline{x}) d \lambda_{t} \\
& +\int_{\tilde{x}}^{k}(1-\alpha) \phi G-k+(\beta-\phi)(1+r)(1-\alpha)(k-x) d \lambda_{t} .
\end{aligned}
$$

When $\beta \in[\underline{\beta}, 1]$ (and $\tilde{x}<\underline{x}$ ) the second term on the right vanishes. As $(1-\alpha) G \phi>k$, the right is strictly larger than $(1-\alpha) y$ and increases in $\beta$, as $r$ and $\tilde{x}$ are constant. If $\lambda_{t}([k, \infty))=0$ capital market equilibrium implies.

$$
\frac{\alpha \psi(1+r)}{1+r \psi} \int_{\underline{x}}^{\tilde{x}}(x-\underline{x}) d \lambda_{t}=\alpha\left(E_{\lambda_{t}} x_{t}-k \int_{\tilde{x}}^{k} d \lambda_{t}\right) .
$$

If this is substituted into (11) when $\lambda_{t}([k, \infty))=0$ we get

$$
\frac{E_{\lambda_{t}} x_{t+1}}{1-\alpha}=y+E_{\lambda_{t}} x_{t}+\int_{\tilde{x}}^{k} \phi G-k+(\beta-\phi)(1+r)(k-x) d \lambda_{t} .
$$

$\lambda_{t}$ has a continuous density function (say $f($.$) ), so we can differentiate this with respect to \beta$.

$$
\begin{aligned}
\frac{\partial E_{t} x_{t+1}}{\partial \beta}= & (1-\alpha) \int_{\tilde{x}}^{k}(k-x)\left(1+r+(\beta-\phi) \frac{\partial r}{\partial \beta}\right) d \lambda_{t} \\
& -\frac{\partial r}{\partial \beta} \frac{\partial \tilde{x}}{\partial r}(1-\alpha)(\phi G-k+(1+r)(\beta-\phi)(k-\tilde{x})) f(\tilde{x})
\end{aligned}
$$


As $\frac{\partial r}{\partial \beta} \leq 0$ and $\frac{\partial \tilde{x}}{\partial r}>0$ the second term on the right is positive. The whole of the right is positive provided the term in the integral is positive, which will be true for $\beta$ sufficiently close to $\phi$.

Part (3): There is no credit rationing so $\tilde{x} \leq(1-\alpha) y$ and (13) becomes

$$
E_{\lambda_{t}} x_{t}=k+\int_{k}^{\infty}(1-\theta(x))(x-k) d \lambda_{t}
$$

By differentiating this with respect to $\beta$ we get

$$
\frac{\partial r}{\partial \beta}=-\frac{\int_{k}^{\infty} \frac{\partial \theta(x)}{\partial \beta}(x-k) d \lambda_{t}}{\int_{k}^{\infty} \frac{\partial \theta(x)}{\partial r}(x-k) d \lambda_{t}} .
$$

There is no credit rationing, so (11) can be re-written as

$$
\begin{aligned}
\frac{E_{\lambda_{t}} x_{t+1}}{1-\alpha} & =y+\phi G-\phi \int_{0}^{k}(1+r)(k-x) d \lambda_{t}+\int_{k}^{\infty}(x-k)(1-\theta+\theta \beta(1+r)) d \lambda_{t} \\
& =y+\phi G+\int_{k}^{\infty}(x-k) d \lambda_{t}+[(\beta-\phi)(1+r)-1] \int_{0}^{k}(k-x) d \lambda_{t} .
\end{aligned}
$$

(Capital market equilibrium implies $\int_{0}^{k}(k-x) d \lambda_{t}=\int_{k}^{\infty} \theta(x-k) d \lambda_{t}$ and this gives the second line.) When $\lambda_{t}$ has a continuous density the above can be differentiated with respect to $\beta$.

$$
\frac{\partial E_{t} x_{t+1}}{\partial \beta}=(1-\alpha) \int_{0}^{k}(k-x) d \lambda_{t}\left[1+r+(\beta-\phi) \frac{\partial r}{\partial \beta}\right]
$$

When there is no credit rationing the effect of $\beta$ on growth depends on the sign of $1+r+(\beta-\phi) \frac{\partial r}{\partial \beta}$. The derivative $\frac{\partial r}{\partial \beta}$ is negative, as an increase in $\beta$ shifts capital supply outwards, so the effect is ambiguous.

By the first order conditions as $x-k \rightarrow \infty$ so $\theta(x) \rightarrow(1-\psi) /(1+r \psi)$. For $x$ large we can approximate $\theta(x)$ by $(1-\psi) /(1+r \psi)$ which is independent of $x$. We can, therefore, approximate $\frac{\partial r}{\partial \beta}$, using (A.2), by

$$
\frac{\partial r}{\partial \beta} \approx-\frac{\frac{\partial \theta}{\partial \beta}}{\frac{\partial \theta}{\partial r}}, \quad \text { where } \quad \theta=\frac{1-\psi}{1+r \psi} .
$$

Some elementary calculus gives

$$
\begin{aligned}
\frac{\partial r}{\partial \beta}(\beta-\phi)+1+r & \approx \frac{-r(1+r)}{\beta(1-\beta)[1+r(1-(1-\gamma) \psi)]}(\beta-\phi)+1+r \\
& =\frac{(1+r)\{\beta(1-\beta)+r \phi-r \beta[\beta+(1-\beta)(1-\gamma) \psi]\}}{\beta(1-\beta)\{1+r[1-\psi(1-\gamma)]\}}
\end{aligned}
$$

This is negative when $\beta$ is close to unity.

Q.E.D.

\section{$\underline{\text { Proof of Proposition } 2}$}


Let $\lambda$ be an initial state. We will first show that there exists a finite integer $N$, independent of $\lambda$ such that $N$ consecutive bad states concentrates the income distribution $f^{N}(\lambda)$ at a point mass at $(1-\alpha) y$.

Given $(1-\alpha) y<k$ there exists a finite $N^{\prime}$ such that no individual has wealth greater than $k$ after $N^{\prime}$ consecutive bad states. By (9) no subsistence individual can move from $x_{t} \leq k$ to $x_{t+1}>k$ in a bad state when

$$
(1-\alpha) \frac{\psi(1+r)}{1+r \psi}(y+k)<k .
$$

(A sufficient condition for this inequality is $(1-\alpha) y<k$.) It is sufficient to show that after $N^{\prime}$ consecutive bad states all individuals with income greater than $k$ are mapped to incomes less than $k$. For $x_{t}>k$ the bequest in bad states is $x_{t+1}=(1-\alpha)\left(y+\left(1-\theta\left(x_{t}\right)\right)\left(x_{t}-k\right)\right) \leq(1-\alpha)\left(y-k+x_{t}\right)$. By iterating we get $x_{N^{\prime}} \leq(y-k)\left(1-(1-\alpha)^{N^{\prime}}\right)(1-\alpha) \alpha^{-1}+(1-\alpha)^{N^{\prime}} x_{0}$. A sufficient condition for no individual to have wealth greater than $k$ after $N^{\prime}$ bad states is

$$
k>(y-k)\left(1-(1-\alpha)^{N^{\prime}}\right)(1-\alpha) \alpha^{-1}+(1-\alpha)^{N^{\prime}} X
$$

for $N^{\prime}$ finite and a sufficient condition for this is $k>(1-\alpha) y$.

When no individual has wealth greater than $k$ there are a finite number, $N^{\prime \prime}$, of consecutive bad states before the income distribution is concentrated at $(1-\alpha) y$. The first step is to show that all individuals with the lowest wealth put all their savings into the mutual fund, $\underline{x}>(1-\alpha) y$. From (5) an equivalent condition for this is $1>\psi(1+(1+r)(1-\alpha))$, and as the right is decreasing in $r$ this describes a lower bound on the interest rate. The value $\tilde{x}$ is adjusted to equate demand and supply of capital to the mutual fund. $\tilde{x} \geq(1-\alpha) y$ when there are no individuals with $x>k$, because otherwise every individual with $x \in[0, k)$ wishes to borrow and there is no supply of capital. But $\tilde{x} \geq(1-\alpha) y$ implies that individuals with $x=(1-\alpha) y$ do not satisfy the strict credit-rationing condition (2).

$$
\phi[G+y+(1+r)(y(1-\alpha)-k)]^{\gamma}+(1-\phi) y^{\gamma} \leq \pi[B+y+(1+r)(y(1-\alpha)-k)]^{\gamma}+(1-\pi) y^{\gamma}
$$

This defines another lower bound on the interest rate. We will show that if $r$ satisfies this second lower bound then $\underline{x}>(1-\alpha) y$. By monotonicity, it is sufficient to show that $1=\psi(1+(1+r)(1-\alpha))$ implies

$$
G+y+(1+r)(y(1-\alpha)-k)>\left(\frac{\pi}{\phi}[B+y+(1+r)(y(1-\alpha)-k)]^{\gamma}+\left(1-\frac{\pi}{\phi}\right) y^{\gamma}\right)^{1 / \gamma} .
$$


It is, therefore, sufficient to show that

$$
1=\psi(1+(1+r)(1-\alpha)) \Longrightarrow G+(1+r)(y(1-\alpha)-k)>\frac{\pi}{\phi}[B+(1+r)(y(1-\alpha)-k)],
$$

or

$$
1=\psi(1+(1+r)(1-\alpha)) \Longrightarrow(1+r)(k-y(1-\alpha))<\frac{\phi G-\pi B}{\phi-\pi} .
$$

The interest rate that solves $1+(1-\alpha)(1+r)=\psi^{-1}=[r \beta /(1-\beta)]^{1 /(1-\gamma)}$ is smaller than $(\beta-(1-$ $\alpha)(1-\beta)(1-\gamma))^{-1}-1$. (The convex function $[r \beta /(1-\beta)]^{1 /(1-\gamma)}$ is bounded below by its tangent at $r=(1-\beta) / \beta$, so the value of $r$ where this tangent intersects $1+(1-\alpha)(1+r)$ is an upper bound on the point of intersection of $1+(1-\alpha)(1+r)$ and $[r \beta /(1-\beta)]^{1 /(1-\gamma)}$. So, a sufficient condition for (A.3) is stated in the Proposition.

When everyone has wealth less than $k$ and $\underline{x}>(1-\alpha) y$, then there are a finite number of bad states before the income distribution is concentrated at $(1-\alpha) y$. As $\underline{x}>(1-\alpha) y$ all individuals with wealth in $[0, \underline{x}]$ and $[\tilde{x}, k]$ are mapped to $(1-\alpha) y$ in bad states, by $(9)$. Once at wealth level $(1-\alpha) y$ they stay there in bad states. To prove the final step it is sufficient to show that there are only a finite number of periods when $\tilde{x}>(1-\alpha) y$, because when $(1-\alpha) y=\tilde{x}$ a bad state implies the bequest distribution is concentrated at $(1-\alpha) y$. Suppose that $\tilde{x}>(1-\alpha) y$, and all the population have inheritances in the interval $[(1-\alpha) y, k]$. For a given supply, $S$, of capital the proportion of borrowers $\omega$ is minimized by assuming that all borrowers have wealth $(1-\alpha) y$ so $\omega \geq S[k-(1-\alpha) y]^{-1}$. The supply of capital $S$ is minimized by assuming that all savers have wealth $(1-\alpha) y$, so $S \geq(1-\omega)(1-\alpha) y$. Eliminating $S$ from these inequalities gives a lower bound on the number of borrowers in any period of $\omega \geq(1-\alpha) y / k$. In successive bad states all borrowers stay at $(1-\alpha) y$, so there can be at most $k /(1-\alpha) y$ bad states before all borrowers have been mapped to $(1-\alpha) y$.

From above, there exists a finite number, $N$ say, such that after $N$ bad states any income distribution is mapped to Dirac distribution at $(1-\alpha) y$. The probability of there not being $N$ consecutive bad states is $1-(1-\beta)^{N}$, so in a sequence of $t>n N$ periods the probability of there not being $N$ consecutive bad states is at most $\left[1-(1-\beta)^{N}\right]^{n}$. The probability that $\left\{\lambda_{t}\right\}$ and $\left\{\lambda_{t}^{\prime}\right\}$ do not have $N$ periods where they both have bad states is at least $\left[1-(1-\beta)^{2 N}\right]^{n}$. Thus

$$
E_{0}\left\|\lambda_{t}-\lambda_{t}\right\| \leq\left[1-(1-\beta)^{2 N}\right]^{n} 1, \quad t>N n
$$

because $\|\cdot\| \leq 1$ and once both process have had $N$ consecutive bad states in the same periods 
$\left\|\lambda_{t}-\lambda_{t}^{\prime}\right\|=0$. Letting $t$ (and therefore $n$ ) tend to infinity proves the proposition.

\section{$\underline{\text { ProOF OF Proposition } 3}$}

Again the proof is by coupling, we will show that there exists a fixed finite sequence of states that maps all income distributions to a point mass at $(1-\alpha) y$. Then, the proof is the same as that given in Proposition 2.

By an identical argument to that used in the proof of Proposition 2 there exists a finite $N$, such that $N$ successive bad states at any $\lambda \in \Lambda$ ensures that no individual has a wealth greater than $k$.

(a) Suppose that $\tilde{x}_{0}<(1-\alpha) y$, by continuity we can choose an interest rate $r^{\prime}$ sufficiently close to zero such that $\tilde{x}_{r^{\prime}}<(1-\alpha) y$, (we use $\tilde{x}_{r^{\prime}}$ to denote the value of $\tilde{x}$ at the interest rate $r^{\prime}$ ). Choose $\underline{\beta}$ sufficiently close to unity such that $\underline{x}>k$ (defined in (5)) for all $\beta>\underline{\beta}$ and $r>r^{\prime}$. Then, the capital market always opens and as $\tilde{x}>(1-\alpha) y$ so $r>r^{\prime}$. Further, all savers put all of their savings in the mutual fund (because no one has wealth greater than $k$ and everyone puts all of their savings into the capital market $\left(\tilde{x} \geq(1-\alpha) y\right.$ implies $\left.\left.r>r^{\prime}\right)\right)$, so one more bad state maps the income distribution to a point mass at $(1-\alpha) y$.

(b) Choose an interest rate $r^{\prime}$ sufficiently close to zero such that $\tilde{x}_{r^{\prime}}<(2-\alpha)(1-\alpha) y$. For this

value $r^{\prime}$ choose $\underline{\beta}$ sufficiently close to unity such that: (i) $\underline{x}>k$ for all $\beta>\underline{\beta}$ and $r>r^{\prime}$, (ii) any type with wealth greater than $k$ puts all their assets in the mutual fund for all $\beta>\underline{\beta}$ and $r>r^{\prime}$. Suppose there have been $N+2$ successive bad states, so at least two bad states have occurred where no player has a wealth greater than $k$. We will show that one good state and then one bad state will map the income distribution to a point mass at $(1-\alpha) y$.

If the capital market is not open after these $N+2$ bad states, then all players put their inheritance in the storage technology and everyone's bequest is in the interval $\left[(1-\alpha) y, \tilde{x}_{0}\right]$. The evolution of wealth is independent of which state occurs. In the second period the lowest wealth is at least $(2-\alpha)(1-\alpha) y$ and the highest wealth is at most $(1-\alpha)\left(y+\tilde{x}_{0}\right)$. The capital market will open and the equilibrium rate of interest ensures $\tilde{x}>(2-\alpha)(1-\alpha) y$ (otherwise there is zero supply of capital). This implies that $r>r^{\prime}$ and all savers put all of their bequests in the risky asset. If a bad state occurs now, the income distribution is mapped to a point mass at $(1-\alpha) y$.

If the capital market does open after $N+2$ bad states, then there are some individuals with sufficient wealth to satisfy the credit rationing constraint. In the previous period it could not have 
been the case that the bad state mapped everyone to $(1-\alpha) y$, so in the previous period $r \leq r^{\prime}$ and $\tilde{x} \in\left(\tilde{x}_{0}, \tilde{x}_{r^{\prime}}\right]$. In the current period the supply and demand of capital are equated. Let $\mu<1$ denote the proportion of individuals who are lenders; we will derive a bound for $\mu$. The maximum supply of capital is $\mu \tilde{x}$, because then the lenders lend all of the maximum feasible endowment. The minimum demand for capital occurs if all borrowers have a large endowment. The borrowers this period were subsistence types last period, so the maximum endowment a borrower can have is $(1-\alpha)\left(\tilde{x}_{r^{\prime}}+y\right)$. Thus the minimum demand for capital is $(1-\mu)\left[k-(1-\alpha)\left(\tilde{x}_{r^{\prime}}+y\right)\right]$. As the minimum demand must be less than the maximum supply

$$
1-\mu<\frac{\tilde{x}}{k+\tilde{x}-(1-\alpha)\left(\tilde{x}_{r^{\prime}}+y\right)} .
$$

Now a good state occurs and there are 3 groups: (1) $\phi(1-\mu)$ daughters of successful projects with wealth at least $(1-\alpha)\left[G+y-\left(1+r^{\prime}\right)[k-(1-\alpha)(\tilde{x}+y)]\right]$. $(2)(1-\phi)(1-\mu)$ daughters of unsuccessful projects with wealth $(1-\alpha) y$. (3) $\mu$ children of subsistence types with wealth no greater than $(1-\alpha)\left(y+\tilde{x}_{r^{\prime}}\left(1+r^{\prime}\right)\right)$.

We will assume that the market clearing interest rate after the good state is such that $r \leq r^{\prime}$ and derive a contradiction, thereby showing that $r>r^{\prime}$. If $r \leq r^{\prime}$, then all of the third class will borrow $\tilde{x} \leq \tilde{x}_{r^{\prime}}<(2-\alpha)(1-\alpha) y$. They will demand at least $\mu\left(k-(1-\alpha)\left(y+\tilde{x}_{r^{\prime}}\left(1+r^{\prime}\right)\right)\right)$ capital. The supply of capital comes from the very poor and the very rich. This is at most

$$
(1-\mu)\left\{(1-\phi)(1-\alpha) y+\phi\left\{(1-\alpha)\left[G+y-\left(1+r^{\prime}\right)[k-(1-\alpha)(\tilde{x}+y)]\right]-k\right\}\right\} .
$$

By using the fact that $r^{\prime}$ can be chosen to make $r$ arbitrarily close to zero and $\tilde{x}, \tilde{x}_{r^{\prime}}$ arbitrarily close to $\tilde{x}_{0}$, and the fact that the greatest feasible supply is larger than the least feasible demand we can get an approximate lower bound on $1-\mu$.

$$
1-\mu \geq \frac{k-(1-\alpha)\left(y+\tilde{x}_{0}\right)}{(1-\phi(1-\alpha))\left[k-(1-\alpha)\left(y+\tilde{x}_{0}\right)\right]+\phi[(1-\alpha) G-k]+(1-\alpha) y}
$$

We have a contradiction if this lower bound on $1-\mu$ is greater than the above upper bound on $1-\mu$ above. This occurs iff

$$
\left(k-(1-\alpha)\left(\tilde{x}_{0}+y\right)\right)^{2}>\tilde{x}_{0}(1-\alpha)\left[y+\phi G-\frac{\phi}{1-\alpha} k-\phi\left(k-(1-\alpha)\left(y+\tilde{x}_{0}\right)\right)\right] .
$$

The RHS of the above is a linear function of $\phi$, when $\phi=1$ and when $\phi=0$ it gives:

$$
\begin{aligned}
\frac{k-(1-\alpha) y}{G} & >\frac{(1-\alpha) \tilde{x}_{0}}{k+\alpha \tilde{x}_{0}-(1-\alpha) y}, \\
\left(k-(1-\alpha)\left(\tilde{x}_{0}+y\right)\right)^{2} & >\tilde{x}_{0}(1-\alpha) y .
\end{aligned}
$$


By applying the upper bound on $\tilde{x}_{0}$ assumed in the Proposition we get the following sufficient condition for a contradiction.

$$
\begin{aligned}
(k-(1-\alpha) y)\left(k-(1-\alpha)^{3} y\right) & >G(2-\alpha)(1-\alpha)^{2} y \\
\left(k-(1-\alpha) y\left(\alpha^{2}-3 \alpha+3\right)\right)^{2} & >\tilde{x}_{0}(1-\alpha)^{2}(2-\alpha) y .
\end{aligned}
$$

A sufficient condition for these two is (15).

Thus in the period where a bad state occurs it must be the case that $r>r^{\prime}$ and all savers are putting all of their capital into the mutual fund. The bad state will then drive all individuals in the economy to wealth level $(1-\alpha) y$.

Q.E.D. 